\title{
From saline to serial FFR measurement - the continued rationale for physiological stenosis assessment in stable coronary artery disease
}

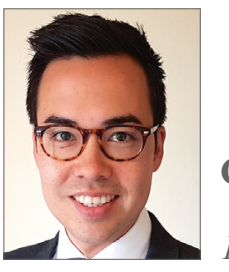

\author{
Christopher M. Cook ${ }^{1 *}$, MBBS, BSc; Takayuki Warisawa', MD; Justin E. Davies², MD, PhD \\ 1. Imperial College London, London, United Kingdom; 2. Hammersmith Hospital, London, United Kingdom
}

In this issue of EuroIntervention are two studies that provide novel findings relevant to the field of coronary physiology. The first of these studies by Fujimori et al explores the potential of the salineinduced $\mathrm{Pd} / \mathrm{Pa}$ ratio (SPR) to identify ischaemia as quantified by fractional flow reserve (FFR) in patients with stable coronary artery disease $(\mathrm{SCD})^{1}$.

\section{Article, see page 898}

The second of these studies, by Xaplanteris et al, determines the evolution of FFR values in intermediate-severity stable coronary lesions, as assessed in patients returning to the coronary catheter laboratory for repeat physiological stenosis assessment ${ }^{2}$.

Article, see page 907

Although these studies are at different ends of the maturation spectrum (the first introducing a new physiological index and the second providing evolutional data on the well-established FFR), both are united by the common theme of supporting the more widespread use of functional stenosis assessment in patients with SCD.

\section{LOW VISCOSITY, HIGH YIELD? SALINE-INDUCED Pd/Pa RATIO PREDICTS THE FUNCTIONAL SIGNIFICANCE OF CORONARY STENOSIS ASSESSED USING FFR}

Despite the strong evidence base to support the use of FFR-guided revascularisation decision making, the adoption of FFR in clinical practice remains stubbornly low ${ }^{3}$. Multiple factors contribute to this. Paramount amongst these is the strength of belief that still persists in the oculostenotic reflex as a reliable marker of ischaemia detection. However, more practical issues around the availability and cost of adenosine and patient side effects associated with pharmacological hyperaemia also contribute.

In the manuscript by Fujimori et al, the authors provide an interesting alternative to both resting and hyperaemic stenosis assessment, namely the SPR. By use of an intracoronary bolus of saline administered at a rate of $2 \mathrm{~mL} / \mathrm{second}$ for a duration of either five heartbeats (SPR-5) or three heartbeats (SPR-3), the authors were able to demonstrate a transient and rapid decline in distal coronary pressure $(\mathrm{Pd})$ that occurred quicker than would be expected if arising from hyperaemia. Following a plateau period, the Pd was gradually noted to return to baseline. With the aortic pressure $(\mathrm{Pa})$ remaining largely unchanged, the dip in $\mathrm{Pd}$ resulted in a lowering of the trans-stenotic pressure ratio $(\mathrm{Pd} / \mathrm{Pa})$, providing a potential hyperaemia-independent index of physiological stenosis assessment. In 414 stenoses from 331 patients, the authors demonstrated strong correlations between SPR-5 or SPR-3 and FFR $(\mathrm{R}=0.941$, $\mathrm{p}<0.001$, and $\mathrm{R}=0.933, \mathrm{p}<0.001$, respectively). Tests of reproducibility were also good - an important consideration for any index wishing to be used in clinical practice. Overall, the authors demonstrated a classification agreement ("diagnostic accuracy") of 
SPR-5 with FFR of $86.3 \%$. The take-home clinical message is that SPR has the potential to decrease the need for adenosine in FFR-based catheter laboratories by up to three quarters. Crucially, unlike the logistically similar contrast-FFR (cFFR) approach, the use of saline as an adjunctive agent avoids the potential for increased quantities of contrast media.

The authors are to be congratulated on their excellently conducted comparison between SPR and FFR for functional stenosis assessment. However, the sole use of FFR as the gold standard measure of ischaemia presents a limitation to their study that should be addressed by subsequent investigation. Specifically, further insight into the ischaemia-detecting capabilities of SPR should be elucidated by additional comparison with other markers of ischaemia such as instantaneous wave-free ratio (iFR), coronary flow reserve or non-invasive positron emission tomography (PET). Secondly, when considering the potential clinical applicability of SPR, owing to the transient physiological state induced by saline infusion, SPR is not able to provide a pressure wire pullback assessment. As the complexity of SCD continues to increase, the ability of a physiological index to quantify individual stenosis severity along the length of a diseased coronary artery will probably become critically important in the planning of physiologically optimised revascularisation strategies ${ }^{4}$.

However, the main point of interest of this study comes when deciding where SPR sits in the spectrum of coronary pressurebased physiological indices. At one end of this spectrum you have the true resting indices such as whole-cycle $\mathrm{Pd} / \mathrm{Pa}$ and iFR. In the middle of the spectrum you have the sub-maximal hyperaemic index of contrast FFR (cFFR). At the extreme end of the spectrum you have FFR - whose experimental basis is predicated on the attainment of maximal hyperaemia ${ }^{5}$. As the authors elude to, the proposed low-viscosity mechanism of SPR does not fit neatly into this classification. This fascinating proposal requires more investigation to appreciate fully how SPR works, and exactly what it is measuring.

\section{STABLE IS STABLE - CORONARY LESION PROGRESSION AS ASSESSED BY FFR AND ANGIOGRAPHY}

Xaplanteris et al provide novel data on the progression of coronary lesions in patients with SCD, assessed both angiographically and also physiologically with $\mathrm{FFR}^{2}$. From a selected population of 331 patients returning to the catheter laboratory for clinically driven repeat FFR measurement, the authors explore the natural history of intermediate lesions using FFR as an endpoint.

Over a median time period of 24 months (17-37 months), the change in percent diameter stenosis was just $2 \%(-5 \%-11 \%)$ and the rate of change of FFR was just $-0.007(-0.028,0.10)$ per year. Considering the variability that exists in any physiological index upon repeated measurements, as well as the variability resulting from different methods of adenosine administration, the results are highly supportive of the stability of coronary lesions in stable coronary artery disease. Although this stability was true at the population level of the study, at the patient level certain individuals did experience large fluctuations in their FFR value upon follow-up assessment. Such findings emphasise the value of repeat physiological assessment as part of a holistic approach to patients with persistent stable angina symptoms.

\section{RUNNING BEFORE WE CAN WALK?}

Common to both studies are questions that remain concerning the underlying physiological mechanisms to explain the results reported. Specifically, without combined coronary pressure and flow data, it is not possible to investigate microcirculatory function. Particularly in the case of FFR, whose action is dependent on maximal vasodilatation of the microcirculation, the unmeasured effects of microvascular disease are especially relevant. As interventionalists, we must strive to consider (and investigate) myocardial ischaemia in terms beyond those simply of coronary pressure.

\section{THE CLINICAL TAKE-HOME MESSAGES}

So, how do we integrate the novel findings provided by these two studies into the contemporary management of patients with SCD? First, we must acknowledge that, for the busy interventional cardiologist, making sense of the growing number of indices proposed for physiological stenosis assessment is potentially bewildering. However, the clinical take-home message is simple. Whichever threeletter acronym you choose to adopt, whether it be FFR, iFR, CFR, HSR (or potentially SPR), the incorporation of coronary physiology into routine revascularisation decision making provides a superior assessment of myocardial ischaemia to that of the angiogram alone.

Second, we must also acknowledge that the evidence supporting the "stability" of "stable" coronary artery disease is abundant. As Xaplanteris and colleagues have identified, there is very little change in functional stenosis severity over time. When assimilated with the clinical outcome results of FAME $2^{6}$ and the recently published pooled analysis of DEFINE-FLAIR and iFR-SWEDE$\mathrm{HEART}^{7}$, the safe deferral of coronary revascularisation is perhaps the most important role for coronary physiology, whichever index you choose to use (Figure 1).

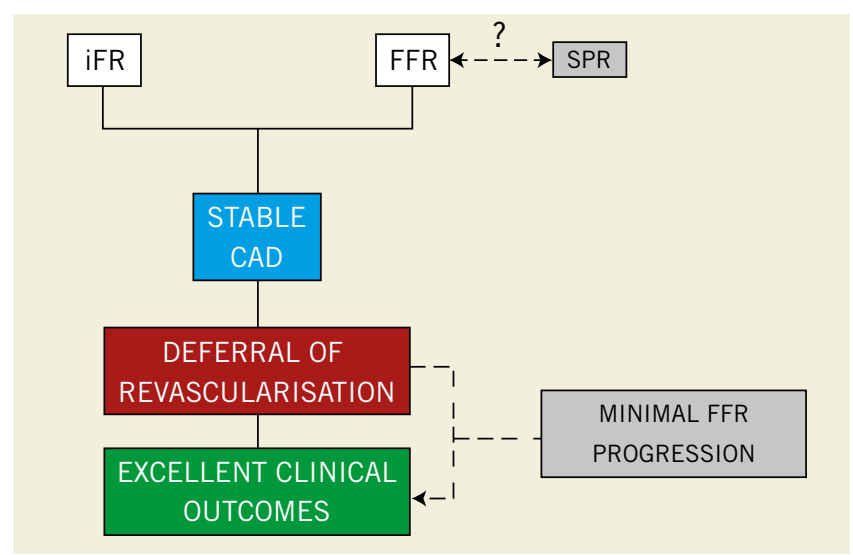

Figure 1. The safety of deferral of stable coronary lesions using coronary physiology. 


\section{Conflict of interest statement}

J. Davies holds patents pertaining to the iFR technology. J. Davies and C. Cook are consultants for Philips Volcano. T. Warisawa has no conflicts of interest to declare.

\section{References}

1. Fujimori Y, Baba T, Yamazaki K, Hashimoto S, Yamanaka Y, Ebisuda K, Kurihara K, Koike N, Takeuchi N, Nishiyama S, Terasawa Y, Wakabayashi T, Imai T. Saline-induced $\mathrm{Pd} / \mathrm{Pa}$ ratio predicts functional significance of coronary stenosis assessed using fractional flow reserve. EuroIntervention. 2018;14:898-906.

2. Xaplanteris P, Ntalianis A, De Bruyne B, Strisciuglio T, Pellicano M, Ciccarelli G, Milkas A, Barbato E. Coronary lesion progression as assessed by fractional flow reserve (FFR) and angiography. EuroIntervention. 2018;14:907-14.

3. Götberg M, Cook CM, Sen S, Nijjer S, Escaned J, Davies JE. The Evolving Future of Instantaneous Wave-Free Ratio and Fractional Flow Reserve. J Am Coll Cardiol. 2017;70:1379-1402.

4. Kikuta Y, Cook CM, Sharp ASP, Salinas P, Kawase Y, Shiono Y, Giavarini A, Nakayama M, De Rosa S, Sen S, Nijjer SS, Al-Lamee R, Petraco R, Malik IS, Mikhail GW, Kaprielian RR, Wijntjens GWM, Mori S, Hagikura A, Mates M, Mizuno A, Hellig F, Lee K, Janssens L, Horie K, Mohdnazri S, Herrera R, Krackhardt F, Yamawaki M, Davies J. Pre-Angioplasty Instantaneous Wave-Free Ratio Pullback Predicts Hemodynamic Outcome In Humans With Coronary Artery Disease: Primary Results of the International Multicenter iFR GRADIENT Registry. JACC Cardiovasc Interv. 2018;11:757-67.

5. Pijls NH, van Son JA, Kirkeeide RL, De Bruyne B, Gould KL. Experimental basis of determining maximum coronary, myocardial, and collateral blood flow by pressure measurements for assessing functional stenosis severity before and after percutaneous transluminal coronary angioplasty. Circulation. 1993;87:1354-67.

6. Xaplanteris P, Fournier S, Pijls NHJ, Fearon WF, Barbato E, Tonino PAL, Engstrøm T, Kääb S, Dambrink JH, Rioufol G, Toth GG, Piroth Z, Witt N, Fröbert O, Kala P, Linke A, Jagic N, Mates M, Mavromatis K, Samady H, Irimpen A, Oldroyd K, Campo G, Rothenbühler M, Jüni P, De Bruyne B; FAME 2 Investigators. Five-Year Outcomes with PCI Guided by Fractional Flow Reserve. N Engl J Med. 2018;379:250-9.

7. Escaned J, Ryan N, Mejía-Rentería H, Cook CM, Dehbi HM, Alegria-Barrero E, Alghamdi A, Al-Lamee R, Altman J, Ambrosia A, Baptista SB, Bertilsson M, Bhindi R, Birgander M, Bojara W, Brugaletta S, Buller C, Calais F, Silva PC, Carlsson J, Christiansen EH, Danielewicz M, Di Mario C, Doh JH, Erglis A, Erlinge D, Gerber RT, Going O, Gudmundsdottir I, Härle T, Hauer D, Hellig F, Indolfi C, Jakobsen L, Janssens L, Jensen J, Jeremias A, Kåregren A, Karlsson AC, Kharbanda RK, Khashaba A, Kikuta Y, Krackhardt F, Koo BK, Koul S, Laine M, Lehman SJ, Lindroos P, Malik IS, Maeng M, Matsuo H, Meuwissen M, Nam CW, Niccoli G, Nijjer SS, Olsson H, Olsson SE, Omerovic E, Panayi G, Petraco R, Piek JJ, Ribichini F, Samady H, Samuels B, Sandhall L, Sapontis J, Sen S, Seto AH, Sezer M, Sharp ASP, Shin ES, Singh J, Takashima H, Talwar S, Tanaka N, Tang K, Van Belle E, van Royen N, Varenhorst C, Vinhas H, Vrints CJ, Walters D, Yokoi H, Fröbert O, Patel MR, Serruys P, Davies JE, Götberg M. Safety of the Deferral of Coronary Revascularization on the Basis of Instantaneous WaveFree Ratio and Fractional Flow Reserve Measurements in Stable Coronary Artery Disease and Acute Coronary Syndromes. JACC Cardiovasc Interv. 2018;11:1437-49. 